\title{
The Empirical Study on the Relationship between International Tourism Development and Economic Growth in Sichuan
}

\author{
Yuanqun Luo \\ College of Economics and Management, Sichuan Agricultural University \\ Room 411, Unit 2, Building 6 \\ Chengdu Campus of Sichuan Agricultural University \\ 211Hui Min road, District Wen Jiang, Chengdu 611130, China \\ Tel: +86-155-207-352-65Ｅ-mail: yuanfang198854@163.com \\ Shiyun Yang \\ College of Economics and Management, Sichuan Agricultural University \\ Room 411, Unit 2, Building 6 \\ Chengdu Campus of Sichuan Agricultural University \\ 211Hui Min road, District WenJiang, Chengdu 611130, China \\ Tel: +86-187-081-134-71Ｅ-mail: yangshiyun0023@hotmail.com \\ Dongmei Li (Corresponding author) \\ College of Economics and Management, Sichuan Agricultural University \\ Chengdu 611130, China \\ Tel: +86-187-801-832-69Ｅ-mail: cndldm@163.com
}

Received: Septmber 28, 2011

Accepted: October 25, 2011 Published: November 21, 2011

doi:10.5430/ijba.v2n4p140

URL: http://dx.doi.org/10.5430/ ijba.v2n4p140

\begin{abstract}
This study applies the co-integration test, and the granger causality test of econometrics to demonstrate the relationship between international tourism and economic growth in Sichuan province. The results show that there is dynamic relation between them, international tourism is the granger cause of economical growth, but it is not obvious that economical growth of Sichuan has promoted international tourism.
\end{abstract}

Keywords: Economic Growth, International Tourism, Co-Integration Test, Granger Causality Test

\section{Introduction}

Sichuan is well known for its beautiful scenery and brilliant historical culture, and has a reputation in China's tourism industry as a province with abundant tourist resources. After over 20 years of Reform and Opening up, the tourism industry had made a great leap forward in Sichuan. In recent years of the increasing rate of Sichuan international tourism over preceding year was more than 20\%. The GDP of Sichuan was increased by $21.62 \%$ to 1.05053 trillion in 2007. More than 121.7 billion were contributed by tourism, which accounted for $11.58 \%$ of its GDP. Meanwhile Sichuan achieved tourism foreign exchange earnings of 512 million USD and received 1.7087 million foreign tourists, which increased $29.55 \%$ and $17.96 \%$ respectively. In 2010, the tourism industry experiencing baptism of the Wenchuan earthquake still showed a good state of development, the domestic tourism market, inbound market and outbound market all kept higher growth rate. The tourism income was increased by 28.1 to188.61 billion. Among them, domestic tourism revenue of 186.2 billion was made and domestic tourists of 271 million were received, which increased $23.8 \%$ and $28.2 \%$ respectively. At the same time, Sichuan achieved tourism foreign exchange earning of 350 million USD and received 1.049 million foreign tourists, which increased $21.5 \%$ and $26.5 \%$ respectively. According to the standard of the pillar industry, its output accounts for at least $8 \%$ of GDP, therefore tourism industry is confirmed as one of the six pillar 
industries in Sichuan. However, in comparison with the reputation of "a great tourism province", international tourism development is far from perfect. According to the statistical yearbook of Sichuan, international tourism of Sichuan ranked 16 in the country in 2007, after the earthquake, the number of visitors decreased rapidly. By 2010, the rank of Sichuan' tourism foreign exchange earnings had fallen to 21. Even comparing with Chongqing, Yunnan and Shanxi, there was a greater gap. It was extremely asymmetric with its advantages of tourist resources.

BRICS (Brazil, Russia, India, Chin, South Africa) made a heated discussion about international tourism development in 2011.China received much concern from the urban representative as a great potential outbound tourism market. Sichuan is a major tourism province, which abounds with quality tourist areas, and some of them are well known in the world. However, international tourism development falls behind, which is not in line with economic globalization. Therefore, it is necessary to discuss dynamic relation mechanism of international tourism development and economic growth by empirical analysis in Sichuan.

\section{Literature Review}

Tourism industry is regarded as one of main economic growth point by many economists as well as keystone industry in China. In recent years, more and more attention is paid to study on the relationship between tourism and economic expansion. Some domestic scholars have made theoretical analysis and empirical test on how tourism leads to economic development. On one hand, some have focused on the relationship between tourism and regional economic growth. For example, Han (Han, 2003) measures status and role of tourism in national economic development in Hainan by using various economic data from 1987 to 2000 . The results show that there is a strong correlation among tourism, primary industry, tertiary industry. Based on Guilin city, Liu (Liu, 2008) discusses the relationship between international tourism and economic growth by using dynamic econometrics model. The results show that although there is a long-term equilibrium relationship between them, it is not significant that international tourism has promoted economic growth. Zhou and Gan (Zhou \& Gan, 2010) use co-integration tests and granger causality test to make a positive normative analysis between them in Shanxi with data from 1990 to 2007 too. The results indicate that there exists dynamic equilibrium relationship as well as reciprocal feedback. This conclusion corresponds to Zhou's study to Sichuan tourism development and economy. On the other hand, some are more inclined to concern with pulling effect of tourism development on the growth of the national economy. Yang (Yang, 2006) applies VAR model and Granger-causality test to make a judgment about relationship between domestic touring consumption and economic growth in China. Bidirectional causality does not exist between them in the short-term nor the long-term. Econometrical methods are used to demonstrate long-term equilibrium relationship between them by $\mathrm{He}$ (He, 2007) either. Furthermore, co-integration coefficient is 0.632 . The empirical results indicate that the development of Chinese tourism have positive effect on economic growth. This conclusion is as same as studies of Liu (Liu, 2007) and Huang (Huang, 2010).

In the academic circles, the study about the relationship between tourism and economic growth based on the concrete region changed to the whole national economy considered in the literature.As for the actual condition of Sichuan province, many academic research focuse on theoretical analysis for tourism, especially domestic tourism. Whereas, there is a lack of empirical study on international tourism development in Sichuan, moreover, the economic impact of tourism foreign exchange earning has no demonstration of normative analysis in Sichuan so far. In view of these, this paper aims at exploring the relationship between international tourism and economic growth in Sichuan with quantitative method. It is desirable that this paper could bring much better ideas into the study of international tourism development of Sichuan.

\section{Variable Selection and Data Description}

\subsection{Variable Selection}

From the growing process of our tourism industry, it can be concluded that inbound tourism had grown slowly before 1993 as a result of limited attention of our national policy. From then on, the impact on domestic tourism and outbound tourism have not been enough attention until the issue of "views on the development of domestic tourism" and the establishment of "China Domestic Tourism Association". Due to the relative lack of statistics and the inconsistent statistical definition of China's inbound tourism statistics, sporadic data are insufficient to explain the positive effect of inbound tourism on economy. Therefore, this paper will choose gross domestic product (GDP) and TR from 1993 to 2000 to measure the total of economic development and international tourism in Sichuan separately. Besides, Consumer Price Index (CPI) is applied to adjust two indicators. This study depends on the publication data from Sichuan statistical yearbook and China statistical yearbook.

\subsection{Data Processing}

Due to the outbreak of SARS in China in 2003, tourism foreign exchange earning of Sichuan saw a sharp drop. In order 
to reject the impact on factors outside of the model, This paper using the measurement software Eviews5.0 makes the model of ARIMA(2,1,2) to fit abnormal data. The fitting-residual is provided in figure1.It shows that the simulated results are quite consistent with the observed ones. As a result, predictive value which will replace true value of tourism foreign exchange earning in 2003 will be used to make empirical study.

\section{Empirical Analyses}

\subsection{Descriptive Statistical Analysis}

This paper uses elastic coefficient to describe relationship between international tourism growth rate and the GDP growth rate. The indicator denotes that $1 \%$ increase of tourism foreign exchange earning produce growth of GDP. Namely elastic coefficient= international tourism growth rate/ the GDP growth rate. As seen in table 1, the average international tourism growth rate is higher than the GDP growth rate during 2000 2010. It is most obvious for the contribution of international tourism to economic growth in 2000, 2001, 2004 and 2009. Considering the influence on the outbreak of SARS in 2003 and Wenchuan earthquake in 2008 in China, elastic coefficient is negative. As a whole, the tourism industry plays an important role in Sichuan's economic growth gradually. It is reasonable to believe that economic growth is more strongly affected by tourism foreign exchange earning in the future along with development of classic tourist routes and increase of whole national economy in Sichuan.

\subsection{Correlation between International Tourism and the Total Industrial Output of the Area.}

First, taking into account the reduction of Sichuan tourism foreign exchange earning after Wenchuan earthquake, this paper only chooses the data from 1993 to 2007 to study. Second, it is commonly believed that there are effects on changed price when different period data are used to make comparative analysis. On the basis of 1993, this paper makes use of CPI to get real TR and GDP to reflect real production activity. Third, this study takes logarithm of GDP and LR to deal with time series with heteroscedasticity. That is to the research on the relationship between GDP and TR convert to LGDP and LTR. Variable coefficients is defined as elasticity dependent variable for independent variable in logarithmic form, namely 1\% change of independent variable produce the percentage of dependent variable. From figure 2 and figure 3, it can be seen that LGDP and LTR two variables show a rising trend with time. There will be spurious regression if we pay no attention to whether the economic phenomenon has relation with others in the regression model, the result will make no sense. For this reason, it is necessary to deal with stationarity test of two time series before building a model.

From the table2, ADF value of LGDP and LTR are larger than the critical value at the $10 \%$ significant level, it means that the series are not stationary. After distinguishing the variables, ADF value of DLGDP and DLTR are less than the critical value at the $5 \%$ and $1 \%$ significant level, the null hypothesis of nonstationarity should be rejected. The first differenced series of LGDP and LTR are stationary based on the unit root tests. Accordingly, the variables were expressed to be I (1).

\subsection{Co-Integration Test}

From the above analysis, those time series of LGDP and LTR are one-order co-integrated, which meet for premise of co-integration test. Co-integration is examined between international tourism and GDP using Engle-Granger two-stage approach (Engle \& Granger, 1987).Regression equation should be established with least square method.

LNGDP=3.050+0.560LNTR

$\mathrm{T}=(5.206)(9.268)$

$R^{2}=0.858, \mathrm{DW}=1.227, \mathrm{~F}=85.904$ (pro=0.000)

The parameters estimated from the model have an optimal goodness of fit. Further more, residual series Et of estimating equation is based on it. Unit root test is used to examine if the co-integration relationship between LnTR and LnGDP exists or not

From the table3, T-statistic (-2.454) is less than the critical value at the $5 \%$ significant level, which draws a conclusion that residual series Et is a stationary series. Which means there exists a long-term and steady dynamic equilibrium relationship between LnTR and LnGDP.

\subsection{Error Correction Model}

This paper based on co-integration relationship build an ECM model on tourism foreign exchange earning and economic growth in Sichuan.

DLNGDP=0.073-0.714ECM(-1)+0.208DLNTR 
(2.471) (-4.000) (2.501)

The coefficient of ECM is a negative which demonstrates there is a reverse revision mechanism in the model.

\subsection{Granger Causality}

The empirical results indicate that there is long-term equilibrium relationship between international tourism and economic expansion. However, it is uncertain whether they are causality of statistical significance between them. It is possible that bilateral granger causality exist between LnTR and LnGDP. The three hypotheses-international tourism growth affects economic expansion, economic expansion affects international tourism growth, and both demonstrate a reciprocal relationship-were tested using the granger causality approach. This study chooses significant level is at 5\%, lag selections are 1, 2, 3 separately. Table 4 provides the results of the granger causality test for three hypotheses.

Bilateral granger causality do not exist between two series with different lag selections. In other words, there is no reciprocal feedback between them. The results are opposite to the view of most scholars and officials.

\section{Conclusion}

From the analysis, it demonstrates that there is a long-term equilibrium relationship between international tourism development and economic growth in Sichuan in spite of no significant short-term equilibrium relation between them. GDP will increase 0.56 percent when the tourism foreign exchange earning is increased by one percent. It means that tourism effect of inbound tourism has contributed positively to economic growth in Sichuan. Therefore, from the strategic angle the government should consider development of international tourism.

The effect of tourism foreign exchange earning of lagging 1 to economic expansion is $40 \%$.In other words, international tourism of lagging 1 has positive impact on economic growth. As a result, international tourism leads to economic development in the long-run in a way. If the GDP of current issue deviate the long-term equilibrium, then the deviation degree will have $71.4 \%$ get fixed next time.

As seen in Table 4, even at the 5\% significant level, the hypothesis is that economic growth -led international tourism is not accepted. On the contrary, international tourism is the granger cause of economical increasing of Sichuan.The combination of results point to a one-way causality for international tourism -driven economic growth. It indicates reciprocal feedback is not formed between them because of position of international tourism in Sichuan. For a long time, Sichuan government takes domestic tourism as basic foothold of tourism, therefore, less attention is paid to international tourism development. It can be seen that international tourism has the huge development potential relying on the abundant tourism resources in Sichuan. In conclusion, In order to make Sichuan transform from a great tourism province to a leading one in China, the government should enhance propaganda and invest in international tourism market. If so, Sichuan will attract more international tourists and international tourism consumption will increase quickly.

\section{References}

Gao, S. (2009). Tourism foreign exchange income and economic growth in China: A panel cointegration approach. Management Science and Engineering.950-955.http://dx.doi.org/10.1109/ICM SE.2009.5318217

Han, Y. (2003). A Positivist Approach to the Impact of the Tourism Industry on Local Economy in Hainan Province. Humanites \&Social Sciences Journal of Hainan University.1, 50-53.

He X. (2007). The Analysis of Co-integration on the Relationship between China's Tourism Development and the Economic Growth.Lan Zhou Xue Kan. 9, 78-80

Huang, W. \& An, L. (2010). The Empirical Test on the Relationship between Development of Inbound Tourism and Economic Growth in China. Statistics and Decision.02, 92-94.

Liu, G. \& Zhang, Z. (2008). An Empirical Study on the Dynamic Relation between International Tourism and Economic Growth of a Region-The Evidence from Guilin. Tourism Forum.1, 107-109

Liu, S. \& Wu Z. (2007). An Empirical Study on Tourism and Economic Growth of China. Systems Engineering.25, 60-64.

Ma, Y. \& Zhou X. (2003). WTO and the New Development of Tourism Industry in China . Beijing: Science press, 47-69.

Yang, Y. (2006). Empirical Analysis on the Relationship between Tourism and Economic Growth in China. Journal of Jiangxi University of Finance and Economics. 2, 101-106.

Yi, D. (2008). Data Analysis and Application Eviews. Beijing: China Renmin University Press, 207-234.

Zhou, L. (2010). Empirical Analysis on the Relationship between Tourism Development and Economic Growth in 
Sichuan. Modern Business Trade Industry.19, 6-8.

Zhou, X. \& Gan X. (2010). Co-integration Analysis of Earnings from International Tourism and the Economic Growth In Shanxi. Journal of Yunnan Normal University.30, 33-37.

Table 1. Relationship between international tourism Growth Rate and the GDP Growth Rate

\begin{tabular}{|c|c|c|c|c|c|c|c|c|c|c|c|}
\hline Year & 2000 & 2001 & 2002 & 2003 & 2004 & 2005 & 2006 & 2007 & 2008 & 2009 & 2010 \\
\hline International Tourism Growth Rate & 25.36 & 36.04 & 20.73 & -25.26 & 93.9 & 9.38 & 25.09 & 29.55 & -69.92 & 85.71 & 21.5 \\
\hline GDP Growth Rate & 5.84 & 9.3 & 10.05 & 12.87 & 19.62 & 15.76 & 16.97 & 21.62 & 19.05 & 13.15 & 19.41 \\
\hline Elastic Coefficient & 4.34 & 3.88 & 2.06 & -1.96 & 4.79 & 0.60 & 1.48 & 1.37 & -3.67 & 6.52 & 1.11 \\
\hline
\end{tabular}

Data source: Sichuan statistical yearbook

Table 2. The result of unit root test

\begin{tabular}{|c|c|c|c|c|c|}
\hline Variable & ADF check value & $1 \%$ level & $5 \%$ level & $10 \%$ level & Conclusion \\
\hline LnGDP & -1.594 (c t 3) & -4.992 & -3.875 & -3.388 & nonstationary \\
\hline DLnGDP & -10.152 (c t 2) & -5.125 & -3.933 & -3.420 & stationary \\
\hline LnTR & -2.002 (c t 3) & -4.800 & -3.791 & -3.342 & nonstationary \\
\hline DLnTR & -4.013 (c 0 3) & -4.057 & -3.120 & -2.701 & stationary \\
\hline
\end{tabular}

1. LN indicates to take logarithm of variables.

2. Three Characters indicate intercept, trend and intercept as well as none respectively in bracket. Lag selections are based on the criterion of SC and AIC.

3. D indicates the first differencing of the variables.

Table 3. Unit root test for Et

\begin{tabular}{|l|r|r|r|l|}
\hline ADF test statistic & T-statistic & Level of significance & Critical value & Conclusion \\
\hline & & $1 \%$ & -2.741 & nonstationary \\
\hline Residual Et & -2.454 & $5 \%$ & -1.968 & stationary \\
\hline & & $10 \%$ & -1.604 & stationary \\
\hline
\end{tabular}

Table 4. Causality tests for LNTR and LNGDP

\begin{tabular}{|c|c|c|c|c|}
\hline null hypothesis & lag & F-statistic & p-value & Conclusion \\
\hline LNTR does not Granger Cause LNGDP & 1 & 11.131 & 0.007 & reject \\
\hline LNGDP does not Granger Cause LNTR & 1 & 0.213 & 0.653 & accept \\
\hline LNTR does not Granger Cause LNGDP & 2 & 44.874 & 0.0004 & reject \\
\hline LNGDP does not Granger Cause LNTR & 2 & 0.464 & 0.645 & accept \\
\hline LNTR does not Granger Cause LNGDP & 3 & 23.952 & 0.002 & reject \\
\hline LNGDP does not Granger Cause LNTR & 3 & 1.234 & 0.390 & accept \\
\hline
\end{tabular}



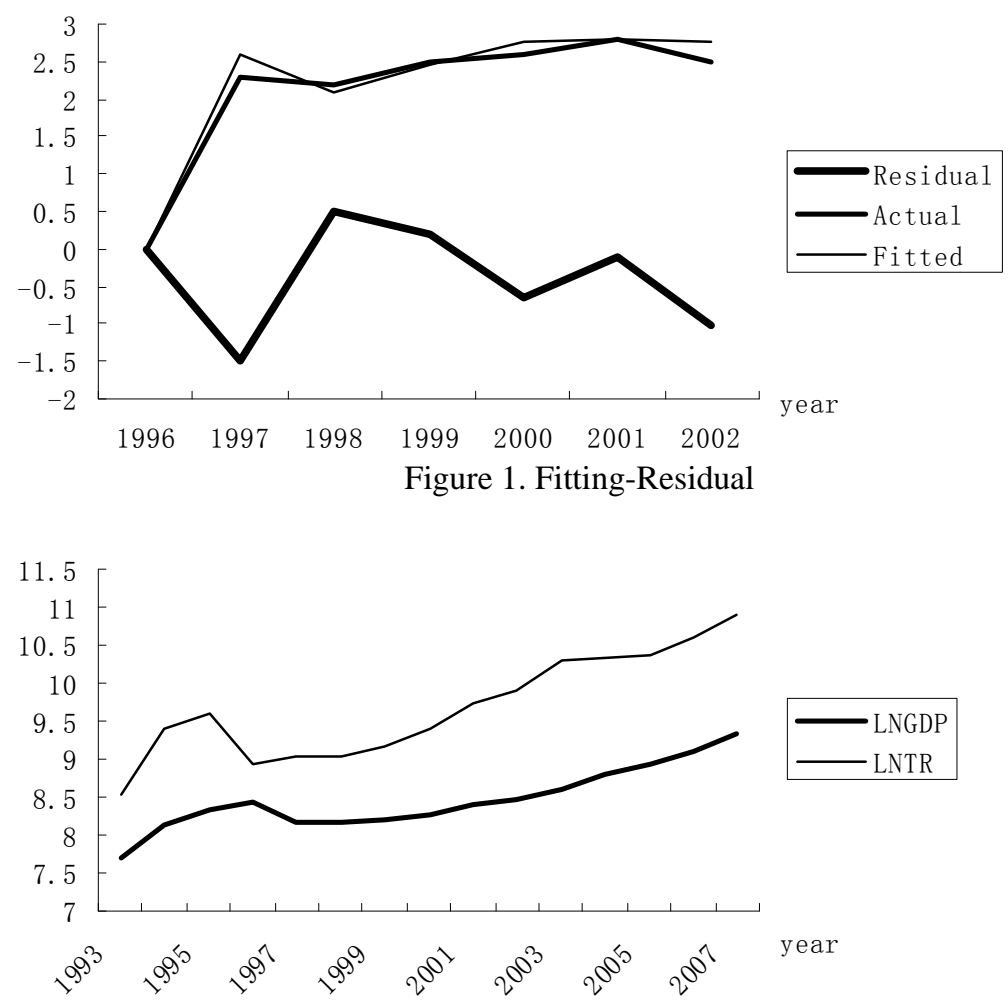

Figure 2. The Trend of LNGDP and LNTR

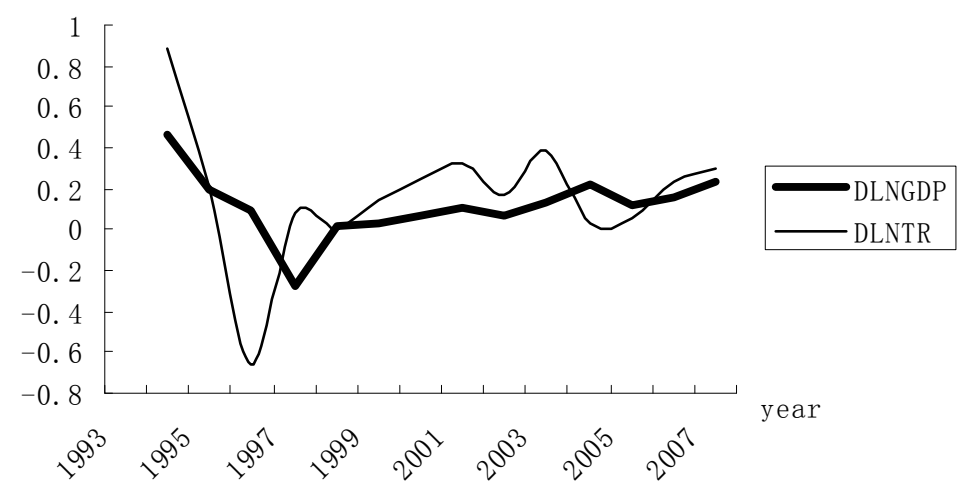

Figure 3. The Trend of DLNGDP and DLNTR 